\title{
EDITORIAL
}

\section{Diversity in wine and medicine}

(c) The Author(s), under exclusive licence to Springer Nature Limited 2021

Bone Marrow Transplantation (2022) 57:521-523;

https://doi.org/10.1038/s41409-021-01549-7

\section{'A lot of different flowers make a bouquet'.}

The first question I asked myself when I was appointed Professor of Academic Medicine and Director of (undergraduate) teaching and learning at Trinity College, Dublin, was: Is there an optimum way of selecting medical students? Apparently not. In Ireland, as in many countries, the number of applicants for places in medical schools far exceeds the number available. The selection process in Ireland depends on the number of 'points' a candidate obtains in the national 'leaving certificate' examination (the socalled CAO system). Although this system has been widely criticised, it provides a degree of fairness and prohibits parents from applying undue pressure to have their children selected for entry. I recollect many phone calls (exclusively from mothers) extolling the family's contribution to the university and asking me to favour the selection of their offspring. Luckily (for me), I always said there was nothing I could do as it all depended on the grades achieved by the prospective candidate and the contribution of the family to the university was irrelevant.

In the UK, selection of medical students depends not only on examination grades but also heavily on an interview with the prospective candidate. While an interview may provide important information, the pressure imposed on the selection board may become overwhelming, especially in a small country (such as Ireland).

In France, each academic institution may have different admission criteria, and medical studies are divided into three cycles. The first cycle (PCEM) lasts 2 years. At the end of the first year, there's a difficult examination which determines who goes into the second year. Usually, only $15-20 \%$ of students pass. This method of selection offers an opportunity for many students to enter medical school but after the first year only students who achieve high grades progress to the next year to continue their medical studies.

In the USA, there is a mixture of state universities and private medical schools. In 2019, a scandal erupted when a criminal conspiracy was uncovered. This revealed an attempt to influence undergraduate admissions, by parents, at several top American universities. To date $>50$ people have been charged with bribery, money laundering and document fabrication and several have received prison sentences. I do not know if any medical schools were involved but the scandal certainly tainted the 'fairness' and diversity of admissions policies.

In a 2021 paper in the New England Journal of Medicine, Morris and et al. report on Diversity of the National Student Body [1]. They found, not surprisingly, that the number of male AfricanAmerican, Hispanic and other racial ethnic group enrollees was well below the percentages of these groups in the national census. Richter et al. writing in the same journal in 2020 point out that women are much less likely to be promoted to higher academic positions than men. The authors offer a number of factors, including an 'old boy's club' mentality which I presume means misogyny [2]. So, diversity is still an issue.

Without going through every country, it is clear that there is no universal acceptable system of selecting medical school entrants and that there is diversity in the system of selection. Whatever about diversity in selection is there diversity in the social class or racial background of enrollees? It seems to me from observation that most medical undergraduates come from middle- or upperclass backgrounds. In Trinity College, Dublin, an attempt was made to widen the social background of students entering medical school. The Trinity Access Programme (TAP) is an attempt to widen the scope of entrants to medical school. A number of TAP students who entered the school of medicine unfortunately dropped out. This was not only from a combination of ongoing

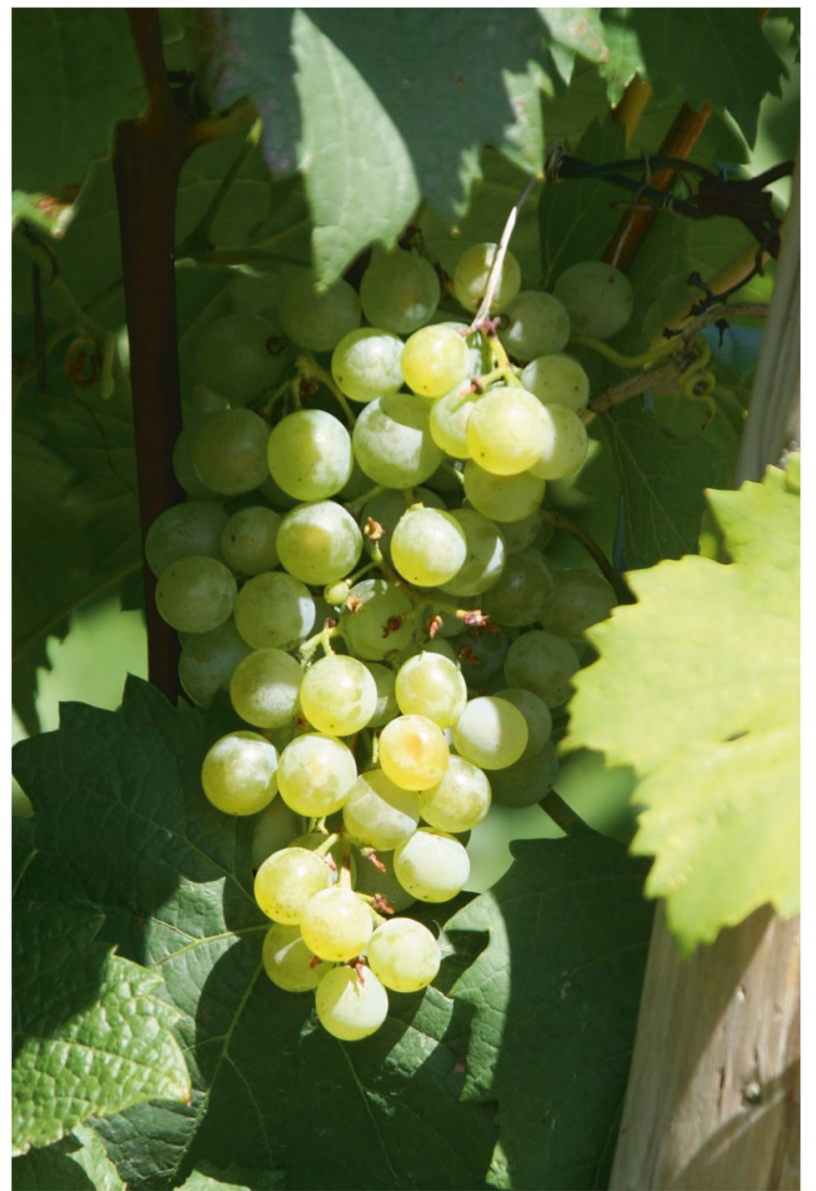

Fig. 1 Grapes. Grüner Veltliner grapes, Schemelsberg hill, Weinsberg, Austria. Creative commons license. 


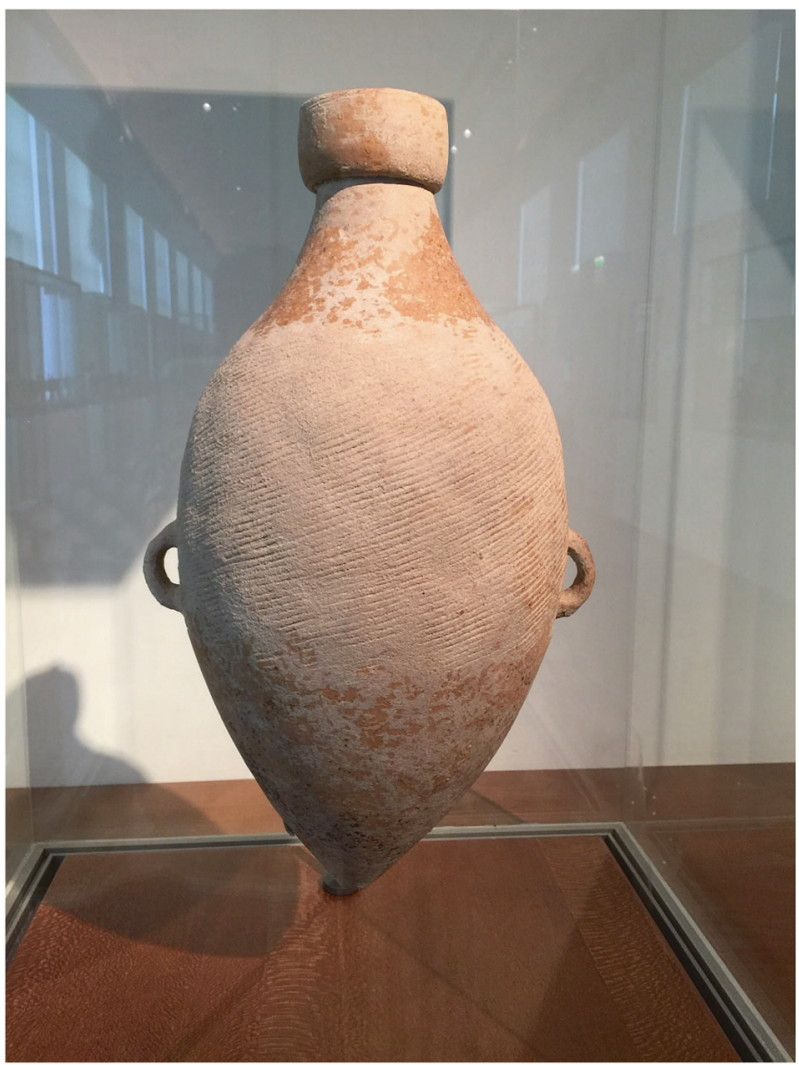

Fig. 2 Amphora. Banpo amphora. Terracotta amphora, Guimet museum, China. Creative commons attribution-Share 4.0 International license.

financial/social difficulties but also snobbery from middle class colleagues.

White, a freelance journalist in the UK, took the medical profession and medical schools to task in 2019 [3]. She says that the UK government's social mobility advisor lambasted the medical profession because too few people from socially and educationally disadvantaged backgrounds were being encouraged to become doctors. Although progress is being made it is very slow. The racial and gender balance has been tackled and in $2014,41 \%$ of entrants to medical school were from ethnic minority backgrounds. In many medical schools in Europe, the gender balance has swung in favour of females with their numbers now exceeding the number of male applicants.

Some countries have introduced another entrance examination (for example, the Health Professions Admission Test, in Ireland) in an effort to increase the percentage of male applicants, but this is of doubtful value and is a highly contested idea. The idea that one's score cannot be improved by extra tuition is clearly fatuous.

Is diversity an issue in the wine trade? Yes. I have already alluded to misogyny [4] in the world of sommeliers, which is a most unpleasant topic but things may be improving in some quarters. Robinson [5] writing in the Weekend FT reports on the recent Taylor's Port Golden Vines scholarships. Apparently 42 wine professionals from all over the world applied for scholarships which would help with the considerable costs of studying for a Master of Wine or a Master Sommelier qualification. Many of the applicants were female and as she says, '....a wine world that can sometimes be seen as a rather stuffy, Anglo-centric institution'. It looks like this is changing, slowly.

Whether you believe in global warming or not, the range of grapes now used for making wine has certainly expanded. Likewise, the number of countries making quality wines is

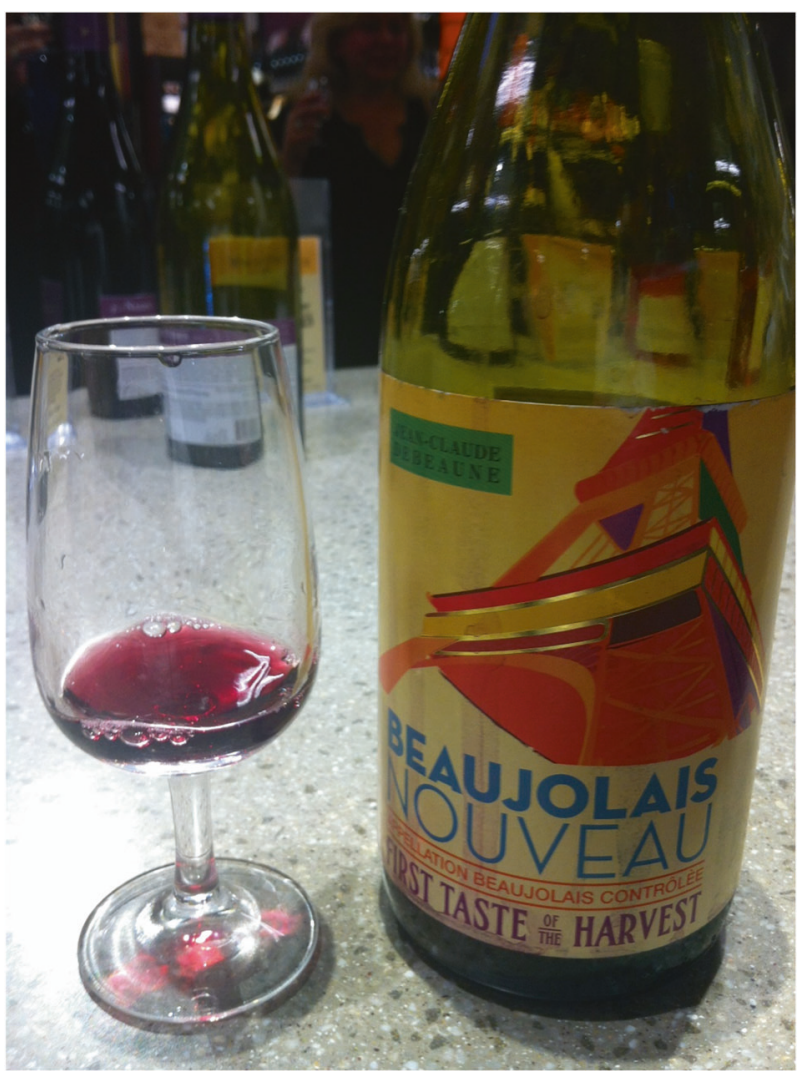

Fig. 3 Beaujolais. Beaujolais wine made from Gamay grape by carbonic maceration using whole grape bunches, fermented in closed containers where $\mathrm{CO}_{2}$ is added to replace $\mathrm{O}_{2}$.

protean. A quick glance at the number of countries making quality wines sold by The Wine Society in the UK reveals at least 17, but excludes China and India. Long gone are the days when the only countries worth considering were France, Germany, Italy, Spain, Australia and the USA.

Diversity in grape varieties is also on the rise. Gapper [6], writing in the Weekend FT, points out that wine farmers will have to adapt to climate change if they are to survive. However, wine farmers not only have to cope with harsh weather conditions [7] but also with snobbery about the provenance of certain wines. A 'burgundy' which is not made in Burgundy may be difficult to sell, but personally I have no problem drinking sparkling wine made by méthode champenoise from the south of England. Grape varieties which make excellent wines include Nero d'Avola, Fiano di Avellino, Falanghina, Greco di Tufo and, of course, the grape Primitivo, from the heel of Italy, is now known (since the 1960s) to be the same as Zinfandel from California. But in an added twist it seems the grape originated in Croatia. Wines made from Grüner Veltliner (Styria south of Vienna), Fig. 1, make a lovely and inexpensive aperitif. Pinot Blanc (Bianco in Italy) is an underrated grape and some wine makers make an excellent, again, inexpensive aperitif. Furmint from Hungary, Assyrtiko from Greece and Bombino Bianco from the heel of Italy [7] are all becoming more popular. Malbec from Mendoza and Cahors in France have recently become very popular. This is, by no means, an exhaustive selection of grapes but points out that there are many varieties and therefore diversity for wine drinkers.

Is there diversity in wine making? Yes. Fermentation may take place in stainless steel tanks, wooden barrels and cement tanks and now amphorae, Fig. 2, are making a comeback. In Beaujolais, most wine makers use carbonic maceration as a means of fermentation, Fig. 3, using whole bunches of grapes, fermenting in 
an anaerobic environment where $\mathrm{CO}_{2}$ replaces $\mathrm{O}_{2}$ so that fermentation takes place without the necessity for yeasts.

One piece of good news, at least for exporters of sparkling wine to the UK, is that Rishi Sunak, the chancellor, announced the end of a premium duty on sparkling wines.

So, when buying wine be brave and do not stick to the wines/ grapes you have always consumed-there is more diversity out there with which to experiment.

Shaun R. McCann (iD ${ }^{1 凶}$

${ }^{1}$ Emeritus, Department of Haematology, Trinity College, Dublin 6, Ireland. ${ }^{\circledR}$ email: shaunrmccann@gmail.com

\section{REFERENCES}

1. Morris DB, Gruppuso PA, McGee HA, Murillo AL, Grover A, Adashi EY. Diversity of the national medical student body-four decades of inequities. N Engl J Med. 2021;384:1661-8. https://doi.org/10.1056/NEJM/Msr2028487.

2. Richter KP, Clark MS, Wick JA, Cruvinel E, Durham D, Shaw P, et al. Women physicians and promotion in academic medicine. N Engl J Med. 2020;383:2140-57. https://doi.org/10.1056/NEJMsa1916935.

3. White C. Shut out: the medical profession's intractable class problem. BMJ. 2019. https://doi.org/10.1136/bmj16433/NEJMsa1916.

4. McCann SR. Sex still matters. Bone Marrow Transplant. 2021. https://doi.org/ 10.1038/s41409-021-01413-8.
5. Robinson J. Raise a glass to diversity. Weekend FT. London, UK: Financial Times; 2021.

6. Gapper J. Climate change tastes bitter to winemakers. Weekend FT. London, UK: Financial Times; 2021.

7. McCann SR. The effect of weather on HCT and vines. Bone Marrow Transplant. 2021;56:2321-3. https://doi.org/10.1038/s41409-0201357-z.

\section{AUTHOR CONTRIBUTIONS}

All the ideas were given and the writing of this article was done by the author.

\section{COMPETING INTERESTS}

The author declares no competing interests.

\section{ADDITIONAL INFORMATION}

Correspondence and requests for materials should be addressed to Shaun R. McCann.

Reprints and permission information is available at http://www.nature.com/ reprints

Publisher's note Springer Nature remains neutral with regard to jurisdictional claims in published maps and institutional affiliations. 